\section{THE GOLDEN MEAN}

To the Editor of Science: With reference to the article on the "Golden Mean" in your issue of April 17, may I recall the fact that in a letter which appeared in Vol. XXXII., p. 625 , I showed that the mean of the $F_{1}$ offspring of two families crossed at random is, on certain assumptions, the geometric mean of the parental averages. I confess that I can not bring Mr. Groth's results for crossing individual plants into line with the theory propounded in my letters, but, at any rate, it is suggestive that a theoretical reason for the appearance of geometric means in connection with inheritance can be given.

$$
\begin{aligned}
& \text { London, } \\
& \text { May 5, } 1914
\end{aligned}
$$

\section{DISAGREEMENTS IN CHEMICAL NOMENCLATURE}

The number of ScIence for January 23 contains an article by Dr. F. W. Clarke which undoubtedly strikes a sympathetic chord in the majority of American chemists. That any chemical element should be given different names by two groups of chemists is indeed lamentable, the more so that each of these groups contains many scientists of enviable reputation who naturally would be expected to place themselves far above the petty jealousies which characterize many societies of less learned persons.

That a scientist who contributes to the known knowledge of chemistry to the extent of discovering a new element should not be granted the privilege of naming that element is anything but just. The columbium-niobium controversy is an excellent example. The discoverer of the element named it columbium; others later took it upon themselves to rechristen the element. The columbiumniobium controversy is not in the least a question of which is the better name-it is a question of bestowing any honor incident to the discovery upon the one to whom it belongs.

But this is merely one of several cases of disagreement in names. In 1798 the French chemist Vauquelin discovered a new element while working with the mineral beryl. Unfor- tunately Vauquelin did not suggest a name for this new element but he did note that the oxide is characterized by a sweetish taste. On account of this property the editors of the Annales de Chimie, the journal in which Vauquelin described his discovery, at once suggested the name glucina for the new earth. The name was immediately adopted by the French. Later the German chemists adopted the name beryllium which they have retained ever since. At the present time the German and Spanish chemists use the name beryllium while the original name glucinum, given by the French, is used by the French, Russian and Italian chemists. Among English chemists as well as those of America, both names are in rather common use. In glancing through twelve chemical text-books in English, all supposedly of college caliber, the author finds that seven make use of the name glucinum whereas only three give preference to the name beryllium. One apparently gives no preference and one does not mention the element except in the table of international atomic weights in which it appears as glucinum. In the publications of the United States Geological Survey the name glucinum is used.

The index of the Journal of the American Chemical Society for the year 1904 contains references to articles on beryllium but none on glucinum. For the year 1905 the index likewise contains references under the name of beryllium only, notwithstanding that one of the articles referred to is a note on the atomic weight of glucinum and does not mention the other name. The index for 1906 contains three beryllium references and one glucinum, while those for the years 1908 and 1909 contain beryllium only. In the Abstract Journal, four beryllium articles and one glucinum are indexed for the first year, 1907, while the index for 1908 contains references to several beryllium articles and also to several on glucinum. In the volumes of the Abstract Journal which have been issued since 1908, the name beryllium alone is used regardless of the name which appeared in the various articles abstracted. 
The element tungsten is the subject of a still more exaggerated disagreement. Scheele was unquestionably the first to mention this element, stating that he had found, in the mineral then known as tungsten but now called scheelite, a new acid to which he gave the name tungstic acid. Two years later, in 1783, it was noted by three Spanish chemists, the d'Elhujar brothers, that the new acid is also present in the mineral wolframite. The German name wolfram was derived from the name of this mineral. At the present time the element is known as wolfram by the Russian and German chemists while the English, French, Spanish and American chemists employ the name tungsten. It is interesting to note that the English and American chemists, although clinging to the historically more correct name, unanimously use the symbol $W$ for this element. On the other hand, the French not only employ the name tungsten but represent it by the symbol $\mathrm{Tu}$.

Still another interesting example. Rutherford and Priestley in 1772 independently demonstrated that after a time an enclosed volume of air no longer supports combustion or respiration. Lavoisier, however, was the first to recognize that this residual air, after removal of the carbon dioxide, is a simple body. On account of its inability to support life, he immediately named the gas azote, deriving the name from a Greek expression meaning literally antagonistic to life. The name nitrogen which the element now commonly bears was first suggested by Chaptal. At the present time the chemists of France and Russia still cling to the original name azote with the symbol Az, while to the chemists of most other nations the element is nitrogen. Nevertheless we still have in English a few relics of the original name, as for example, the names hydrazoic acid, hydrazine, azine and azole.

The adoption or use of a name other than the one originally given to an element by its rightful discoverer is by no means an indication that the discovery is discredited. Although the German chemists unanimously em- ploy the name wolfram, they nevertheless do not hesitate to attribute the discovery to Scheele. Again, these same chemists invariably concede Hatchett to be the discoverer of columbium, although they have substituted and use the name niobium erroneously given to the element by Rose some forty years later. In all probability the greatest argument which the chemists of certain nations can offer today for endorsing the name niobium is the common use which that name has had in their respective countries since the days of Heinrich Rose.

It is unfortunate indeed that there should be lack of unity amongst scientists as to the names and symbols for such fundamental bodies as the chemical elements, but it is still more unfortunate that the chemists of any one land should be divided in their selection of a name for an element as we Americans are with respect to glucinum. A solution of the entire question of names and symbols could be brought about by the appointment of an international committee definitely instructed to waive all petty jealousy and, in a spirit of all fairness, diligently to search the literature, consider all claims of priority and finally report on the original and therefore most proper name for each element. That the chemists of various nations would agree to the appointment of a committee so instructed is entirely possible but very improbable. Furthermore, it is extremely doubtful if a report submitted by such a committee would be adopted by more than one third of the chemists of chemical societies to-day. It would, however, be a comparatively simple matter for American chemists to intrust the settlement of this question to a carefully chosen committee in order that we Americans might use uniform names and symbols although unable to agree entirely with the chemists of other nations.

\section{H. B. NoRTH}

Rutgers College, New BRunswick, N. J.

\section{THE PROFESSOR AND THE INSTITUTION}

In America, we have in name freedom of speech; in fact there are considerable areas of 